\title{
A prospective comparison of cold snare polypectomy using traditional or dedicated cold snares for the resection of small sessile colorectal polyps
}

\section{(ㄷ)(우우}

\author{
Authors \\ Nauze ${ }^{1}$, William Kemp ${ }^{1}$, Stuart Roberts ${ }^{1}$, Gregor Brown ${ }^{1}$ \\ Institutions \\ 1 Department of Gastroenterology, Alfred Hospital, \\ Monash University, Melbourne, Victoria, Australia 3004 \\ 2 Biostatistics, Faculty of Medicine, Nursing and Health \\ Sciences, Monash University, Melbourne, Victoria, \\ Australia 3004
}

Jeremy P. Dwyer ${ }^{1}$, Jonathan Y. C. Tan ${ }^{1}$, Paul Urquhart ${ }^{1}$, Robyn Secomb ${ }^{1}$, Catherine Bunn ${ }^{1}$, John Reynolds ${ }^{2}$, Richard La

submitted 2.10.2016

accepted after revision 22.5.2017

\author{
Bibliography \\ DOI https://doi.org/10.1055/s-0043-113564 | \\ Endoscopy International Open 2017; 05: E1062-E1068 \\ (c) Georg Thieme Verlag KG Stuttgart · New York \\ ISSN 2364-3722
}

Corresponding author

Associate Professor Gregor Brown, Head of Endoscopy, Alfred Hospital, 55 Commercial Rd, Melbourne, VIC 3004, Australia

Fax: +61-3-90762757

g.brown@alfred.org.au

\section{ABSTRACT}

Background and study aims The evidence for efficacy and safety of cold snare polypectomy is limited. The aim of this study was to assess the completeness of resection and safety of cold snare polypectomy, using either traditional or dedicated cold snares.
Patients and methods This was a prospective, non-randomized study performed at a single tertiary hospital. Adult patients with at least one colorectal polyp (size $\leq 10 \mathrm{~mm}$ ) removed by cold snare were included. In the first phase, all patients had polyps removed by traditional snare without diathermy. In the second phase, all patients had polyps removed by dedicated cold snare. Complete endoscopic resection was determined from histological examination of quadrantic polypectomy margin biopsies. Immediate or delayed bleeding within 2 weeks was recorded.

Results In total, 181 patients with 299 eligible polyps ( $\mathrm{n}=$ 93 (173 polyps) traditional snare group, $\mathrm{n}=88$ (126 polyps) dedicated cold snare group) were included. Patient demographics and procedure indications were similar between groups. Mean polyp size was $6 \mathrm{~mm}$ in both groups $(P=$ 0.25). Complete polyp resection was $165 / 173$ (95.4\%; 95 $\% \mathrm{Cl} 90.5-97.6 \%)$ in the traditional snare group and 124 / $126(98.4 \%$; $95 \% \mathrm{Cl} 93.7-99.6 \%)$ in the dedicated cold snare group $(P=0.16)$. Serrated polyps, compared with adenomatous polyps, had a higher rate of incomplete resection ( $7 \%$ vs. $2 \%, P=0.03$ ). There was no statistically significant difference in the rate of immediate bleeding (3\% vs. $1 \%, P$ $=0.41$ ) and there were no delayed hemorrhages or perforations.

Conclusions Cold snare polypectomy is effective and safe for the complete endoscopic resection of small $(\leq 10 \mathrm{~mm})$ colorectal polyps with either traditional or dedicated cold snares.

\section{Introduction}

Colorectal cancer (CRC) is a leading cause of cancer-related morbidity and mortality, and colonoscopy is effective at reducing the risk through the removal of adenomatous polyps [1, 2]. Techniques for endoscopic polyp resection include cold or hot biopsy forceps and cold or hot snare, and significant variation exists in clinical practice [3]. Cold snare polypectomy is used to remove colonic polyps up to $10 \mathrm{~mm}$ in size through transection of the polyp base along with a $1-2 \mathrm{~mm}$ cuff of nor- mal mucosa to achieve complete resection. This technique avoids the use of electrocautery and its potential for deep thermal injury associated delayed bleeding or perforation [4].

The effectiveness of colonoscopy in reducing CRC is dependent on accurate detection and complete resection of colorectal polyps. CRC diagnosed soon after colonoscopy ("interval" CRC) may be due to incompletely resected polyps in $19 \%$ of cases [5]. Significant variation exists in rates of complete resection depending on the polypectomy technique used. Cold biopsy forceps achieved a complete resection rate of $39 \%$ of di- 
minutive polyps in a study where endoscopic mucosal resection (EMR) of the polyp base was used to assess for residual polyp [6]. Incomplete polyp resection can be present in 10.1\% (95\% Cl: $6.9 \%-13.3 \%$ ) of polypectomies of $5-20 \mathrm{~mm}$ sessile polyps using snare polypectomy [7]. Cold snare polypectomy resulted in a statistically significantly higher complete resection rate compared with cold forceps polypectomy for polyps $\leq 7 \mathrm{~mm}$ using endoscopic mucosal resection (EMR) to assess for residual polyp tissue ( $97 \%$ vs $83 \%, P=0.01$ ) [8]. Dedicated cold snares with thinner monofilament wires and diamond-shaped snare loops are now available and may be more effective than traditional snares with thicker, braided current-carrying wires and oval-shaped snare loops for the resection of small colorectal polyps. In a study of 76 patients with 210 eligible polyps ( $\leq 10 \mathrm{~mm}$ diameter), complete resection was statistically significantly greater with dedicated cold snares than with traditional cold snares ( $91 \%$ vs $79 \%, P=0.015$ ) [9].

In addition to complete polyp resection, another important consideration with regard to polypectomy is safety. Post-polypectomy bleeding can affect $1 \%$ of patients [10] and increases to over $10 \%$ in patients taking warfarin [11]. Cold snare polypectomy typically eliminates the risk of delayed bleeding and perforation associated with electrocautery, and immediate bleeding is typically capillary in nature and of little clinical significance. Due to its favorable safety profile, cold snare polypectomy is the preferred resection technique for small colorectal polyps in patients taking warfarin [12]. The aim of this study was to assess prospectively the completeness of endoscopic resection and safety of cold snare polypectomy using either traditional snares or dedicated cold snares.

\section{Patients and methods}

\section{Study design and population}

This was a prospective, non-randomized comparison of two methods of cold snare polypectomy. Adult patients undergoing colonoscopy for routine indications with at least one sessile (Paris classification $0-\mathrm{Is}$ ) or flat (Paris classification 0-Ila, 0 IIb or 0 - IIc) colorectal polyp (size $\leq 10 \mathrm{~mm}$ ) were included. Prospectively enrolled patients who underwent cold snare polypectomy in 2015 using the Exacto ${ }^{\circledR}$ snare (US endoscopy, Ohio, United States) were compared with a previously reported cohort of patients from 2011 and 2014 for which the SnareMaster ${ }^{\circledR}$ snare (Olympus, Tokyo, Japan) was used $[13,14]$. Patients with pedunculated polyps or who underwent concurrent hot snare polypectomy or EMR were excluded. The study was performed at The Alfred Hospital in Melbourne, Australia. The study protocol was approved by the Human Ethics Committee at The Alfred Hospital and all patients gave their written informed consent.

\section{Endoscopy proceduralist, equipment, and procedure}

Procedures were performed by experienced gastroenterology consultants and/or consultant-supervised trainees using variable stiffness, high definition colonoscopes (Olympus 180 or 190-series, Tokyo, Japan). In the first phase of the study during

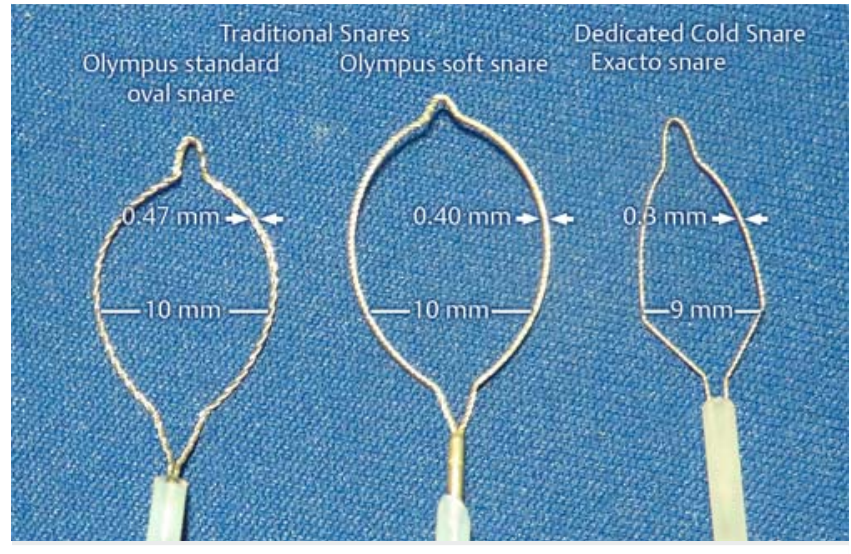

- Fig. 1 Traditional and dedicated cold snares.

2011 and 2014, all patients had polyps removed by traditional snare without diathermy (see - Fig. 1, SnareMaster ${ }^{\circledR}$ snare, loop size $10 \mathrm{~mm}, 0.40$ or $0.47 \mathrm{~mm}$ wire diameter). In the second phase during 2015, all patients had polyps removed by dedicated cold snare (see $>$ Fig. 1, Exacto ${ }^{\circledR}$ snare, loop size $9 \mathrm{~mm}$, $0.30 \mathrm{~mm}$ wire diameter). Polyp size was estimated using the size of the snare catheter or the open snare loop. Cold snare polypectomy was performed as previously described [15], namely the polyp was positioned at 5 o'clock with the fully opened snare placed over the polyp ensuring a $\geq 1-2 \mathrm{~mm}$ margin of normal mucosa. With gentle forward pressure on the snare catheter, the snare was closed and the polyp transected in a continuous motion without tenting. Following retrieval of the polyp through the suction channel into a polyp trap, careful white light and narrow-band imaging (NBI) inspection of the polyp defect was performed and further snare resection could be performed for any residual polyp. After polyp resection was considered complete macroscopically, quadrantic biopsies were obtained from the resection margin. Piecemeal resected polyps could still be considered completely resected histologically if biopsies of polypectomy margins were free from residual polyps. Cold snare polypectomy of $\leq 10 \mathrm{~mm}$ sessile or flat polyps could be performed in patients taking antiplatelet or anticoagulant therapy in accordance with our protocol. Prophylactic placement of hemostatic clips post-polypectomy was not routinely performed in anticoagulated patients but could be placed in patients with prolonged immediate bleeding (>30 seconds) at the discretion of the endoscopist.

\section{Outcome variables}

Following the colonoscopy, the endoscopist completed a data sheet recording the procedure indication, antiplatelet or anticoagulant therapy, consultant or trainee performed procedure, snare type used, size, number and location of polyps resected and retrieved, the presence of any immediate bleeding, and whether any hemostatic therapy was performed post-polypectomy. Two weeks following the procedure, patients were reviewed either in the clinic or by phone and histopathology results and any adverse events documented. The primary outcome of completeness of endoscopic resection was determined 
Assessed for eligibility

( $n=200$ patients, $n=347$ polyps)

\begin{tabular}{|c|c|}
\hline$\downarrow$ & $\downarrow$ \\
\hline $\begin{array}{c}\text { Traditional snare } \\
\text { ( } n=105 \text { patients, } \\
n=203 \text { polyps) }\end{array}$ & $\begin{array}{l}\text { Dedicated cold snare } \\
\qquad(n=95 \text { patients, } \\
n=144 \text { polyps })\end{array}$ \\
\hline $\begin{array}{l}30 \text { excluded polyps } \\
\text { - } 27 \text { normal } \\
\text { histology } \\
\text { - } 1 \text { no base } \\
\text { biopsies } \\
\text { - } 2 \text { no follow-up }\end{array}$ & $\begin{array}{l}18 \text { excluded polyps } \\
\text { - } 11 \text { normal } \\
\text { histology } \\
\text { - } 7 \text { concomitant } \\
\text { EMR }\end{array}$ \\
\hline $\begin{array}{l}\text { Traditional snare } \\
\text { ( } n=93 \text { patients, } \\
n=173 \text { polyps) }\end{array}$ & $\begin{array}{l}\text { Dedicated cold snare } \\
\qquad(n=88 \text { patients, } \\
n=126 \text { polyps })\end{array}$ \\
\hline
\end{tabular}

Fig. 2 Enrolment flow chart.

from histological examination of the polypectomy specimen and quadrantic biopsies taken from the margin of the polypectomy site.

\section{Sample size and statistical analyses}

The sample size was not determined statistically, but pragmatically set at 100 patients per group as the study was limited not only by the number of referrals for colonoscopy, and subsequent consents, but also by the study duration. As this was a non-randomized study, and to allow for clustering of polyps within individuals, the method of Generalized Estimating Equations, as implemented in $\mathrm{SAS}^{\circledR}$ version 9.4, was used to estimate rates of complete resection and their $95 \%$ confidence intervals in each group. Two-sided $P$ values are reported for comparisons of the groups with the caveat that the study was not a randomized study; Fisher's exact test was used for categorical variables and Student's $t$ test for continuous variables.

\section{Results}

\section{Patients}

In total, 200 patients with 347 polyps were initially recruited for the study ( Fig. 2). Thirty polyps (27 normal histology, 1 no base biopsies taken, 2 no follow-up) and 18 polyps (11 normal histology, 7 concomitant EMR) were excluded from the traditional snare and dedicated cold snare groups, respectively, so 181 patients with 299 eligible polyps ( $n=93$ (173 polyps) traditional snare group, $\mathrm{n}=88$ (126 polyps) dedicated cold snare group) were included in the final analysis. Patient demographic data is summarized in > Table $\mathbf{1}$. There were no associations between snare-type cohort and gender, age or indication. More

- Table 1 Patient demographic data at baseline, overall and by type of snare.

\begin{tabular}{|c|c|c|c|c|}
\hline & \multirow{2}{*}{$\begin{array}{l}\text { Overall } \\
\text { n (\%) }\end{array}$} & \multicolumn{2}{|l|}{ Snare type } & \multirow[t]{2}{*}{$P$ value } \\
\hline & & $\begin{array}{l}\text { Traditional snare } \\
\text { n (\%) }\end{array}$ & $\begin{array}{l}\text { Dedicated cold snare } \\
\text { n (\%) }\end{array}$ & \\
\hline Patients & 181 & 93 & 88 & \\
\hline Male gender & $115(64)$ & $60(65)$ & $55(63)$ & 0.88 \\
\hline Age, mean (range) & $64(28-89)$ & $65(29-89)$ & $63(28-83)$ & 0.34 \\
\hline \multicolumn{5}{|l|}{ Indication } \\
\hline - Screening/surveillance & $125(69)$ & $64(69)$ & $61(69)$ & 1.0 \\
\hline - Iron deficiency anemia & $18(10)$ & $8(9)$ & $10(11)$ & 0.62 \\
\hline - Symptoms & $37(20)$ & $21(23)$ & $16(18)$ & 0.58 \\
\hline - Other & $1(1)$ & $0(0)$ & $1(1)$ & 0.49 \\
\hline Antithrombotic agent used & $27(15)$ & $21(23)$ & $6(7)$ & 0.01 \\
\hline - Aspirin & $17(9)$ & $13(14)$ & $4(5)$ & 0.04 \\
\hline - Clopidogrel & $1(1)$ & $0(0)$ & $1(1)$ & 0.49 \\
\hline - Warfarin & $9(5)$ & $8(9)$ & $1(1)$ & 0.04 \\
\hline \multicolumn{5}{|l|}{ Proceduralist } \\
\hline - Consultant & $38(21)$ & $27(29)$ & $11(13)$ & 0.01 \\
\hline - Fellow & $138(76)$ & $65(70)$ & $73(83)$ & 0.05 \\
\hline - Registrar & $5(3)$ & $1(1)$ & $4(5)$ & 0.20 \\
\hline
\end{tabular}


- Table 2 Polypectomy outcomes and histopathology.

\begin{tabular}{|c|c|c|c|c|}
\hline & \multirow{2}{*}{$\begin{array}{l}\text { Overall } \\
\text { n (\%) }\end{array}$} & \multicolumn{2}{|l|}{ Snare type } & \multirow[t]{2}{*}{$P$ value } \\
\hline & & $\begin{array}{l}\text { Traditional snare } \\
\text { n (\%) }\end{array}$ & $\begin{array}{l}\text { Dedicated cold snare } \\
\text { n (\%) }\end{array}$ & \\
\hline Total polyps & 299 & 173 & 126 & \\
\hline Polyps per patient, mean [SD] & $2[1]$ & $2[1]$ & $1[1]$ & 0.01 \\
\hline Polyp size, mean [SD] & $6[2]$ & $6[2]$ & $6[2]$ & 0.25 \\
\hline \multicolumn{5}{|l|}{ Polyp size } \\
\hline . $1-5 \mathrm{~mm}$ & $158(53)$ & $84(49)$ & $74(59)$ & 0.10 \\
\hline - $\geq 6 \mathrm{~mm}$ & $141(47)$ & $89(51)$ & $52(41)$ & 0.10 \\
\hline \multicolumn{5}{|l|}{ Polyp location } \\
\hline - Right colon ${ }^{1}$ & $188(63)$ & $98(57)$ & $90(71)$ & 0.01 \\
\hline - Left colon² & $111(37)$ & $75(43)$ & $36(29)$ & 0.01 \\
\hline Suction pseudopolyp technique & $5(2)$ & $5(3)$ & 0 & 0.08 \\
\hline Piecemeal resection & $28(9)$ & $22(13)$ & $6(5)$ & 0.03 \\
\hline Complete resection rate & 289/299 (97) & $165 / 173(95)$ & $124 / 126(98)$ & 0.16 \\
\hline \multicolumn{5}{|l|}{ Polyp histology } \\
\hline - Tubular adenoma & $194(65)$ & $120(69)$ & $74(59)$ & 0.07 \\
\hline - Tubulovillous adenoma & $24(8)$ & $15(9)$ & $9(7)$ & 0.67 \\
\hline - Serrated adenoma & $36(12)$ & $15(9)$ & $21(17)$ & 0.05 \\
\hline - Hyperplastic & $45(15)$ & $23(13)$ & $22(17)$ & 0.33 \\
\hline
\end{tabular}

patients in the traditional snare group were taking antithrombotic agents ( $23 \%$ vs. $7 \%, P=0.01$ ) and had a consultant proceduralist $(P=0.01)$.

\section{Polypectomy}

Polyp characteristics and polypectomy outcomes are shown in - Table 2. Significantly more polyps were resected per patient in the traditional snare group than in the dedicated cold snare group ( 2 vs. $1, P=0.01$ ). Mean polyp size was $6 \mathrm{~mm}$ in both groups $(P=0.25)$ and there was no statistically significant difference in size category ( $\leq 5 \mathrm{~mm}, \geq 6 \mathrm{~mm}$ ) between groups. More polyps in the dedicated cold snare group were located in the right colon (proximal to splenic flexure) (71\% vs. $57 \%, P=$ $0.01)$. The suction pseudopolyp technique was used for 5 (3\%) polyps in the traditional snare group and none in the dedicated cold snare group. Piecemeal resection was used more frequently in the traditional snare group than in the dedicated cold snare group ( $13 \%$ vs. $5 \%, P=0.03$ ). The rate of successful polyp retrieval was $100 \%$ in both groups.

The complete polyp resection rate was 165/173 (95.4\%; 95 $\% \mathrm{Cl} 90.5-97.6 \%)$ in the traditional snare group and $124 / 126$ (98.4\%; $95 \% \mathrm{Cl} 93.7-99.6 \%)$ in the dedicated cold snare group $(P=0.16)$. The difference between the snare-type cohorts remained unchanged when adjusted for proceduralist, antith- rombotic use, and polyp size. There were more sessile serrated adenomas in the dedicated cold snare group (17\% vs. $9 \%, P=$ $0.05)$.

\section{Factors associated with incomplete resection}

Univariate analysis showed no association between complete polyp resection and snare type, resection method (en bloc vs piecemeal), polyp size, polyp location or proceduralist ( $>$ Table 3). Conversely, polyps with serrated or hyperplastic histology had a higher rate of incomplete resection compared with adenomatous polyps ( $7 \%$ vs. $2 \%, P=0.03$ ).

\section{Post-polypectomy adverse events}

There was no difference in the rate of immediate post-polypectomy bleeding between groups ( $\vee$ Table 4 ). There was one case of immediate bleeding in the traditional snare group with five polyps resected on warfarin requiring hemoclips and one case in the dedicated cold snare group. There were no delayed post-polypectomy bleeds or perforations in either group. 
- Table 3 Univariate analysis for predictors of incomplete polyp resection.

\begin{tabular}{|c|c|c|c|}
\hline Variable & $\begin{array}{l}\text { Incomplete } \\
\text { resection } \\
n(\%)\end{array}$ & $\begin{array}{l}\text { Complete } \\
\text { resection } \\
\mathbf{n}(\%)\end{array}$ & $\begin{array}{l}P \\
\text { value }\end{array}$ \\
\hline Total polyps & 10 & 289 & \\
\hline \multicolumn{4}{|l|}{ Snare type } \\
\hline - Traditional snare & $8(5)$ & $165(95)$ & 0.20 \\
\hline - Dedicated cold snare & $2(2)$ & $124(98)$ & \\
\hline \multicolumn{4}{|l|}{ Resection technique } \\
\hline - En bloc resection & $9(3)$ & $262(97)$ & 1.0 \\
\hline - Piecemeal resection & $1(4)$ & $27(96)$ & \\
\hline \multicolumn{4}{|l|}{ Polyp size } \\
\hline . $1-5 \mathrm{~mm}$ & $6(4)$ & $152(96)$ & 0.75 \\
\hline - $\geq 6 \mathrm{~mm}$ & $4(3)$ & $137(97)$ & \\
\hline \multicolumn{4}{|l|}{ Polyp location } \\
\hline - Right colon ${ }^{1}$ & $4(2)$ & $184(98)$ & 0.18 \\
\hline - Left colon² & $6(5)$ & $105(95)$ & \\
\hline \multicolumn{4}{|l|}{ Proceduralist } \\
\hline - Consultant & $4(6)$ & $64(94)$ & 0.24 \\
\hline - Fellow/Registrar & $6(3)$ & $225(97)$ & \\
\hline \multicolumn{4}{|l|}{ Polyp histology } \\
\hline - Serrated/hyperplastic & $6(7)$ & $75(93)$ & 0.03 \\
\hline - Adenomatous & $4(2)$ & $214(98)$ & \\
\hline
\end{tabular}

\section{Discussion}

Cold snare polypectomy is rapidly replacing hot snare and biopsy forceps as the preferred technique for the removal of colorectal polyps up to $10 \mathrm{~mm}[16,17]$. Cold snare polypectomy reduces the risks of delayed bleeding and perforation associated with electrocautery and is more effective than cold biopsy forceps resection for diminutive polyps [18]. However, over $10 \%$ of sessile polyps may be incompletely resected by snares [7], which may result in residual polyp regrowth and ultimately progression to CRC [5]. Dedicated cold snares, with thinner monofilament wire and a unique diamond-shaped snare loop, may be more effective at tissue transection and complete polyp resection than traditional snares. In this study, we prospectively assessed completeness of endoscopic resection and safety of cold snare polypectomy of colorectal polyps $\leq 10 \mathrm{~mm}$ using either traditional snares or dedicated cold snares. We found very high rates of complete resection (95.4\% traditional snare vs. 98.4\% dedicated cold snare, $P=0.16$ ) with both snare types and an excellent safety profile with no delayed post-polypectomy bleeds or perforations.

Significant variability in polypectomy technique exists amongst endoscopists and there is limited evidence to guide best practice. Cold snare polypectomy is superior to cold forceps polypectomy for complete resection of small colorectal polyps $(>3 \mathrm{~mm})[8,18,19]$. Hot biopsy forceps are associated with incomplete polyp resection [20] and increased risk of deep thermal injury and therefore should be avoided [21]. In comparison to hot snare polypectomy, cold snare polypectomy avoids the use of electrocautery and the associated risks of perforation and delayed bleeding. Recent studies have compared dedicated cold snares with traditional snares with respect to completeness of endoscopic resection and safety. Horiuchi et al. showed a higher complete resection rate with a dedicated cold snare (Exacto ${ }^{\circledR}$, US endoscopy) than with a traditional cold snare (SnareMaster ${ }^{\circledR}$, Olympus) ( $91 \%$ vs $\left.79 \%, P=0.015\right)$ in patients with colorectal polyps $\leq 10 \mathrm{~mm}$ [9]. Similarly, Din et al. found higher complete endoscopic excision with the Exacto ${ }^{\circledR}$ snare compared to a $0.47 \mathrm{~mm}$ wire diameter oval Olympus

- Table 4 Adverse events per polypectomy.

\begin{tabular}{|l|l|l|l|}
\hline & $\begin{array}{l}\text { Overall } \\
\mathbf{n}(\%)\end{array}$ & $\begin{array}{l}\text { Snare type } \\
\text { Traditional snare } \\
\mathbf{n}(\%)\end{array}$ & $\begin{array}{l}\text { Dedicated cold snare } \\
\mathbf{n}(\%)\end{array}$ \\
\hline Total polyps & 299 & 173 & 126 \\
\hline Immediate bleeding1 & $6(2)$ & $5(3)$ & $1(1)$ \\
\hline Endoscopic therapy & & & \\
\hline - Hemoclip & $6(2)$ & $5(3)$ & $1(1)$ \\
\hline Delayed bleeding ${ }^{2}$ & 0 & 0 & 0 \\
\hline Perforation & 0 & 0 & 0 \\
\hline $\begin{array}{l}1 \\
\text { Immediate bleeding defined as prolonged post-polypectomy bleeding (>30 seconds). }\end{array}$ \\
\hline Delayed bleeding defined as any significant gastrointestinal bleeding requiring hospital admission or repeat endoscopy within 2 weeks. \\
\hline
\end{tabular}


mini snare (90.2\% vs $73.3 \%, P<0.05)$, without a statistically significant difference in complete histological excision $(73.3 \%$ vs $65.2 \%, P=0.4$ ), in patients with 3 to $7 \mathrm{~mm}$ colorectal polyps [22]. Features of the Exacto ${ }^{\circledR}$ snare which may result in superior complete polyp resection compared with traditional snares include a thinner snare wire $(0.3 \mathrm{~mm})$ and a unique shield shape of the open snare loop. Both these features may result in more effective tissue capture and transection than thicker wire $(0.40$ $\mathrm{mm}$ and $0.47 \mathrm{~mm}$ ) traditional snares, therefore increasing the likelihood of complete cold snare polyp resection.

In comparison to these studies, we found a high complete polyp resection rate with traditional snares $(0.40$ or $0.47 \mathrm{~mm}$ snare wire diameter; $95.4 \%$ complete excision) without diathermy and with dedicated cold snares ( $98.4 \%$ complete excision), with no statistically significant difference between the snare types. The higher rate of complete polyp excision in our study may reflect correct cold snaring technique. Correct cold snare polypectomy technique, as recently outlined by Hewett [16], focuses on securing a $2-4 \mathrm{~mm}$ margin of normal mucosa around the polyp prior to transection to ensure complete histological eradication. Differences in complete polyp excision rates between studies may also result from differing methods of determining complete histological excision. In this study, complete polyp resection was determined by histological examination of the polypectomy specimen and quadrantic biopsies taken from the polypectomy site margin. In the study by Horiuchi et al. [9], en bloc specimens were mounted on plates before formalin fixation, which is commonly performed in Japan, and histological resection was considered complete if vertical and lateral margins were clear of polyp tissue. Din et al. [22] used indigo carmine to target biopsies from areas of residual tissue post-polypectomy, as well as the margin and base using large capacity biopsy forceps. The best method for determining complete polyp resection is endoscopic mucosal resection of the polypectomy base; however, this may not be feasible in all cases and is associated with increased risk of complications, most notably delayed bleeding and perforation, compared with biopsies.

This study also showed that polyps with serrated histology (sessile serrated adenomas or hyperplastic polyps) were associated with incomplete resection compared with adenomatous polyps ( $7 \%$ vs. $2 \%, P=0.03)$. In the CARE study, incomplete resection of polyps 5 to $20 \mathrm{~mm}$ in size was greater for sessile serrated adenomas (SSAs) than for conventional adenomas (31\% vs. $7 \%, P<0.001)$ [7]. Incomplete resection of SSAs may be due to their subtle endoscopic appearance including flat morphology, similar color to normal mucosa, clouded surface, irregular shape, and indistinct borders [23]. SSAs are precursors for sporadic microsatellite unstable CRC, which are located almost exclusively in the proximal colon and disproportionately contribute to interval CRC [24]. Improving the endoscopic recognition and complete resection of SSAs would likely improve the effectiveness of colonoscopy, particularly in the right colon. Further studies are needed addressing whether complete resection of serrated polyps may be improved by adjunctive techniques such as chromoendoscopy or EMR.
Our study confirms the safety of cold snare polypectomy of small colorectal polyps. In this study, 6 (2\%) polyps in two patients, one of whom was receiving warfarin therapy, had intraprocedural bleeding requiring hemostatic clipping and there were no cases of delayed bleeding or perforation. Variable rates of immediate bleeding, which are typically clinically insignificant, have been reported following cold snare polypectomy. Horiuchi et al. recorded an immediate bleeding rate of $19 \%$ and $21 \%$ with dedicated and traditional cold snares, respectively [9]. Other studies have reported no immediate or early bleeding with cold snare polypectomy [22,25-27]. Delayed bleeding or perforation has not been reported in several trials of cold snare polypectomy $[9,22,25,28]$. In our study, $15 \%$ of patients underwent cold snare polypectomy on antiplatelet or anticoagulant medications. In a randomized trial of cold snare versus hot snare polypectomy in anticoagulated patients with colorectal polyps $\leq 10 \mathrm{~mm}$, cold snare polypectomy resulted in significantly less immediate bleeding and no cases of delayed bleeding, whereas $14 \%$ of hot snare patients required endoscopic hemostasis for delayed bleeding [12]. Cold snare polypectomy is therefore the technique of choice in patients on antithrombotic agents but further randomized trials are needed to confirm safety.

Limitations to this study include a non-randomized and single center study design. However, because blinding of the endoscopist to the snare type was not possible, randomization may not have reduced any bias. Furthermore, because traditional snares were used in 2011 and 2014 and dedicated snares in 2015, there was potential time bias due to more experience and improved technique with cold snares in the latter group. Piecemeal resection of polyps was permitted in this study when incomplete polyp resection was noted endoscopically. This was present in $9 \%$ of patients overall and was statistically significantly higher in the traditional snare group than in the dedicated cold snare group ( $13 \%$ vs. $5 \%$ ). This may have resulted in a higher complete histological resection rate than if en bloc resection alone was permitted. However, as polyps up to $10 \mathrm{~mm}$ were included in this study and because the maximum open snare sizes of the traditional and dedicated cold snares were $10 \mathrm{~mm}$ and $9 \mathrm{~mm}$, respectively, it was deemed necessary in some cases to perform piecemeal resection of larger polyps in order to achieve a $1-2 \mathrm{~mm}$ cuff of normal mucosa in the resection. The higher complete polyp resection rate $(95.4 \%)$ achieved with the traditional snare in this study compared with previous studies $(65.2-79 \%)$ [9,22] may have resulted in our study being under-powered to detect a statistically significant difference in complete resection rates between snare types.

In summary, this study confirms the efficacy and safety of cold snares for the complete resection of small $(\leq 10 \mathrm{~mm})$ colorectal polyps. Traditional snares and dedicated cold snares had complete resection rates of $95 \%$ and $98 \%$, respectively. Only polyps with serrated histology, compared with adenomatous polyps, were associated with higher rates of incomplete resection. Cold snare polypectomy should be utilized for the resection of all small colorectal polyps. Improvements in polyp detection, cold snare technique (focusing on ensuring complete 
polyp resection), and endoscopic technology such as dedicated cold snares, may increase the impact of colonoscopy on the burden of CRC.

\section{Competing interests}

Exacto ${ }^{\circledR}$ and SnareMaster ${ }^{\circledR}$ snares were provided by the manufacturers US endoscopy (distributed by Device Technologies, 1 Garigal Rd, Beltrose, NSW 2085, Australia) and Olympus (distributed by Olympus Australia, 3 Acacia Place, Notting Hill, VIC 3168, Australia), respectively.

\section{References}

[1] Zauber AG, Winawer S], O’Brien M] et al. Colonoscopic polypectomy and long-term prevention of colorectal-cancer deaths. NEJM 2012; 366: $687-696$

[2] Winawer S], Zauber AG, Ho MN et al. Prevention of colorectal cancer by colonoscopic polypectomy. The National Polyp Study Workgroup. NEJM 1993; 329: $1977-1981$

[3] Singh N, Harrison M, Rex DK. A survey of colonoscopic polypectomy practices among clinical gastroenterologists. Gastrointest Endosc 2004; 60: 414-418

[4] Fatima H, Rex DK. Minimizing endoscopic complications: colonoscopic polypectomy. Gastrointest Endosc Clin N Am 2007; 17: 145 156

[5] Robertson D], Lieberman DA, Winawer S] et al. Colorectal cancers soon after colonoscopy: a pooled multicohort analysis. Gut 2014; 63: 949-956

[6] Efthymiou M, Taylor AC, Desmond PV et al. Biopsy forceps is inadequate for the resection of diminutive polyps. Endoscopy 2011; 43: $312-316$

[7] Pohl H, Srivastava A, Bensen SP et al. Incomplete polyp resection during colonoscopy - results of the complete adenoma resection (CARE) study. Gastroenterology 2013; 144: 74-80

[8] Kim JS, Lee BI, Choi $\mathrm{H}$ et al. Cold snare polypectomy versus cold forceps polypectomy for diminutive and small colorectal polyps: a randomized controlled trial. Gastrointest Endosc 2015; 81: 741 - 747

[9] Horiuchi A, Hosoi K, Kajiyama M et al. Prospective, randomized comparison of 2 methods of cold snare polypectomy for small colorectal polyps. Gastrointest Endosc 2015; 82: 686-692

[10] Heldwein W, Dollhopf M, Rosch T et al. The Munich Polypectomy Study (MUPS): prospective analysis of complications and risk factors in 4000 colonic snare polypectomies. Endoscopy 2005; 37: 1116 1122

[11] Hui AJ, Wong RM, Ching JY et al. Risk of colonoscopic polypectomy bleeding with anticoagulants and antiplatelet agents: analysis of 1657 cases. Gastrointest Endosc 2004; 59: 44 - 48

[12] Horiuchi A, Nakayama Y, Kajiyama M et al. Removal of small colorectal polyps in anticoagulated patients: a prospective randomized com- parison of cold snare and conventional polypectomy. Gastrointest Endosc 2014; 79: 417 - 423

[13] Urquhart P, Brown G]. Su1426. The effectiveness of cold snare polypectomy for the removal of small sessile colonic polyps. Gastrointest Endosc 2012; 75: AB328

[14] Tan J, La Nauze R, Roberts SK et al. 714. The efficacy and safety of cold snare polypectomy. Gastrointest Endosc 2015; 81: AB164

[15] Hewett DG, Rex DK. Colonoscopy and diminutive polyps: hot or cold biopsy or snare? Do I send to pathology? Clin Gastroenterol Hepatol 2011; 9: $102-105$

[16] Hewett DG. Cold snare polypectomy: optimizing technique and technology (with videos). Gastrointest Endosc 2015; 82: 693-696

[17] Din S, Ball A], Taylor E et al. Polypectomy practices of sub-centimeter polyps in the English Bowel Cancer Screening Programme. Surg Endosc 2015; 29: $3224-3230$

[18] Lee CK, Shim JJ, Jang JY. Cold snare polypectomy vs. Cold forceps polypectomy using double-biopsy technique for removal of diminutive colorectal polyps: a prospective randomized study. Am J Gastroenterol 2013; 108: $1593-1600$

[19] Park SK, Ko BM, Han JP et al. A prospective randomized comparative study of cold forceps polypectomy by using narrow-band imaging endoscopy versus cold snare polypectomy in patients with diminutive colorectal polyps. Gastrointest Endosc 2016; 83: 527-532

[20] Peluso F, Goldner F. Follow-up of hot biopsy forceps treatment of diminutive colonic polyps. Gastrointest Endosc 1991; 37: 604-606

[21] Metz AJ, Moss A, McLeod D et al. A blinded comparison of the safety and efficacy of hot biopsy forceps electrocauterization and conventional snare polypectomy for diminutive colonic polypectomy in a porcine model. Gastrointest Endosc 2013; 77: 484-490

[22] Din S, Ball A], Riley SA et al. Cold snare polypectomy: does snare type influence outcomes? Dig Endosc 2015; 27: 603-608

[23] Hazewinkel Y, Lopez-Ceron M, East JE et al. Endoscopic features of sessile serrated adenomas: validation by international experts using high-resolution white-light endoscopy and narrow-band imaging. Gastrointest Endosc 2013; 77: 916 - 924

[24] Sweetser S, Jones A, Smyrk TC et al. Sessile serrated polyps are precursors of colon carcinomas predominantly with deficient DNA mismatch repair. Clin Gastroenterol Hepatol 2016; 14: 1056-1059

[25] Din S, Ball A], Riley SA et al. A randomized comparison of cold snare polypectomy versus a suction pseudopolyp technique. Endoscopy 2015; 47: $1005-1010$

[26] Gomez V, Badillo RJ, Crook JE et al. Diminutive colorectal polyp resection comparing hot and cold snare and cold biopsy forceps polypectomy. Results of a pilot randomized, single-center study (with videos). Endosc Int Open 2015; 3: E76-80

[27] Ichise $Y$, Horiuchi A, Nakayama $Y$ et al. Prospective randomized comparison of cold snare polypectomy and conventional polypectomy for small colorectal polyps. Digestion 2011; 84: 78-81

[28] Repici A, Hassan C, Vitetta E et al. Safety of cold polypectomy for $<10 \mathrm{~mm}$ polyps at colonoscopy: a prospective multicenter study. Endoscopy 2012; 44: $27-31$ 